\title{
Contribution of BRCA / germ-line mutations to breast cancer in Greece: a hospital-based study of 987 unselected breast cancer
}

\section{cases}

\section{S Armaou', M Pertesi', F Fostira', G Thodi', PS Athanasopoulos', S Kamakari', A Athanasiou ${ }^{3}$, H Gogas ${ }^{4}$, D Yannoukakos', G Fountzilas ${ }^{5,6}$ and I Konstantopoulou*,}

'Molecular Diagnostics Laboratory, I/R-RP, National Center for Scientific Research 'Demokritos', Aghia Paraskevi, I 5310 Athens, Greece; BioGenomica, Center for Genetic Research and Analysis, Papanikoli 4, 15232 Athens, Greece; ${ }^{3}$ Department of Medical Oncology A, Metaxa Cancer Hospital, 18537 Piraeus, Greece; ${ }^{4}$ First Department of Internal Medicine, University of Athens, Laiko Hospital, I I 527 Athens, Greece; ${ }^{5}$ Department of Medical Oncology, Papageorgiou Hospital, Aristotle University of Thessaloniki School of Medicine, 56429 Thessaloniki, Greece; ${ }^{6}$ Hellenic Cooperative Oncology Group, Hadjikonstanti 18, II524 Athens, Greece

BACKGROUND: In most Western populations, 5-10\% of all breast cancer cases can be attributed to major genetic factors such as predisposing mutations in BRCA I and BRCA2, with early-onset cases generally considered as an indicator of genetic susceptibility. Specific BRCA I and BRCA2 mutations or different mutation frequencies have been identified in specific populations and ethnic groups. Previous studies in Greek breast and/or ovarian cancer patients with family history have shown that four specific BRCA I mutations, c.5266dupC, GI738R, and two large genomic rearrangements involving deletions of exons 20 and 24, have a prominent function in the population's BRCA/ and BRCA2 mutation spectrum.

METHODS: To estimate the frequency of the above mutations in unselected Greek breast cancer women, we screened 987 unselected cases independently of their family history, collected from major Greek hospitals.

RESULTS: Of the 987 patients, 26 (2.6\%) were found to carry one of the above mutations in the BRCAI gene: 13 carried the c.5266dupC mutation (1.3\%), 6 carried the exon 24 deletion (0.6\%), 3 carried the exon 20 deletion (0.3\%), and 4 carried the GI738R mutation (0.4\%). Among 140 patients with early-onset breast cancer ( $<40$ years), I 4 carried one of the four mutations (10.0\%).

CONCLUSION: These results suggest that a low-cost genetic screening for only the four prominent BRCA I mutations may be advisable to all early-onset breast cancer patients of Greek origin.

British Journal of Cancer (2009) I 0 I, 32-37. doi:I0.1038/sj.bjc.6605।I5 www.bjcancer.com

Published online 2 June 2009

(c) 2009 Cancer Research UK

Keywords: $B R C A$ /; BRCA2; hereditary breast-ovarian cancer; genetic screening; germ-line mutation; founder mutation

Breast cancer is the most common malignancy in women, affecting approximately 1 in 10 women. Incidence rates are increasing annually and it is estimated that by year 2010 there will be 1.5 million new cases worldwide (Parkin et al, 2005). Germ-line mutations in predisposing genes, mainly BRCA1 (MIM 113705) and BRCA2 (MIM 600185) but also other genes critical for genome integrity such as CHEK2, PALB2, ATM, p53, PTEN, STK11, CDH1 and more, are responsible for about half of familial breast cancer cases, which in turn represent one-third of all breast cancers (Walsh and King, 2007). Mutations are often found in families burdened with many cases of breast and/or ovarian cancer, usually occurring at an earlier age. Assessing an at-risk individual's mutation status is a procedure growing in clinical importance from an optional genetic test to a powerful predictive tool, as prevention protocols for carriers become established and new treatment

*Correspondence: Dr I Konstantopoulou;

E-mail: reena@rrp.demokritos.gr

Received 17 February 2009; revised 6 May 2009; accepted 6 May 2009; published online 2 June 2009 options emerge (Robson and Offit, 2007; De Greve et al, 2008). However, full $B R C A 1$ and $B R C A 2$ screening still remains a tedious task due to gene length, the plethora of mutations, the high frequency of $B R C A 1$ rearrangements requiring special technical approach, and mutation spectrum differences in different populations. This procedure remains too expensive to target a broader population part and cannot be routinely applied in less privileged areas and countries.

Several studies have shown that in certain countries and ethnic communities the BRCA1 and BRCA2 mutation spectrum is limited to a few founder mutations (Neuhausen, 2000; Fackenthal and Olopade, 2007; Ferla et al, 2007), a fact that allows more costeffective screening of individuals with low mutation probability. Testing could thus be made accessible to more women. From such broader studies, it has emerged that many women found to carry a mutation do not have a documented previous family history of the disease.

We have shown in our previous work on the BRCA1 and BRCA2 mutation spectrum of the Greek population that four BRCA1 mutations account for $54 \%$ of all mutations detected in both genes, 
whereas the rest are unique or low-frequency mutations, reflecting the population's genetic heterogeneity (Konstantopoulou et al, 2008). As our previous studies involved individuals with medium to strong family history, our aim here is to expand the population screened to breast cancer patients independently of their family history of breast or ovarian cancer. A hospital-based cohort of 987 unselected breast cancer cases was analysed to determine the frequency of the four most common mutations of the BRCA1 gene. In that way, a population-specific, cost-effective, mini protocol for genetic testing of hereditary breast cancer is applied to a wider population setting and is evaluated for clinical usefulness. As an early age at breast cancer onset is generally considered an indicator of genetic susceptibility, it is interesting to assess whether and in what degree mutation frequencies differ between unselected cases and cases with disease onset before age 40 .

\section{MATERIALS AND METHODS}

\section{Patients}

Screening for the four BRCA1 mutations was performed in 987 unselected female breast cancer patients with histologically verified diagnosis, regardless of family history. The samples were collected from several major hospitals in collaboration with the Hellenic Cooperative Oncology Group (HECOG), representing major geographical areas of Greece, such as Athens metropolitan area, Thessaloniki, Ioannina, Patras, and Crete (Chania). The study was approved by ethics and research committees of the hospitals and was in agreement with the 1975 Helsinki statement, revised in 1983. Informed consent was obtained from all individuals before genetic analysis was performed. The patients' mean age of breast cancer diagnosis was 53.9 years, ranging from 20 to 87 years old. Our cohort included 140 patients with early-onset ( $<40$ years) breast cancer $(14.19 \%$ of the total), whereas 382 patients $(38.66 \%)$ were diagnosed before the age of 50. Among the 987 patients tested, 6 have developed bilateral breast cancer $(0.6 \%), 8$ have developed both breast and ovarian cancer $(0.8 \%)$, and 10 have developed both breast and another type of cancer (1.0\%). Breast and/or ovarian cancer family history was reported by 111 patients (11\%). The minimum criterion to classify a patient as having family history was one additional first- or second-degree relative with breast cancer diagnosed before 50 years or ovarian cancer at any age. Family history was obtained after an interview with each patient. Once a mutation was confirmed in an independent blood sample, results were communicated to patients by the Oncology units participating in the HECOG network. For patients found to be carriers, there were ensuing counselling efforts.

\section{Mutation detection}

Genomic DNA was extracted from peripheral blood lymphocytes using a standard chloroform-isoamyl alcohol protocol. The quantity and the quality of the DNA samples was determined by UV absorbance using a NanoDrop 1000 (Thermo Fisher Scientific, MA, USA) and agarose gel electrophoresis. Detection of the BRCA1 c.5266dupC (5382insC) mutation was performed using a previously described mutagenically separated polymerase chain reaction (PCR) assay (Chan et al, 1999). The BRCA1 G1738R mutation was detected using an RFLP-based method as previously described in Anagnostopoulos et al (2008). To detect the genomic rearrangements involving $B R C A 1$ exons 20 and 24, we used diagnostic PCR primers as described in Armaou et al (2007). In all cases, PCR amplifications were performed in a Veriti 96-Well Thermal Cycler (Applied Biosystems, Foster City, CA, USA). PCR products were electrophoresed through $2.5 \%$ agarose gel and visualised by ethidium bromide staining. To confirm each detected mutation, we directly sequenced PCR products using an ABI
PRISM Dye Deoxy Terminator Kit v3.1 (Applied Biosystems) in ABI 310 Genetic Analyzer (PerkinElmer, Applied Biosystems), according to manufacturer's instructions. Primer sequences and protocols are available upon request.

\section{RESULTS}

We have screened 987 samples from unselected breast cancer patients for the four most common BRCA1 mutations in Greece: c.5266dupC (5382insC), G1738R (c.5212G > A), the $3.2 \mathrm{~kb}$ deletion of exon 20 (c.5256_5277+3179del3200), and the $4.4 \mathrm{~kb}$ deletion of exon 24 (c.5468-285_5592 + 4019del4429_insCACAG).

The distribution of the age of onset among all patients studied and among patients with family history is shown in Figure 1. Comparison of the two categories clearly shows a much earlier disease onset in the latter group, with the majority developing breast cancer before 50 years. The mean age of diagnosis for patients with family history was 46.3 years, eight years lower than that for the whole cohort (53.9 years).

Twenty-six patients $(2.6,95 \%$ CI $1.6-3.6 \%)$ were found to carry one of the four BRCA1 mutations presented in this study. Mutation c.5266dupC (5382insC) was detected in 13 breast cancer patients $(1.3,95 \%$ CI $0.6-2.0 \%)$, the exon 24 deletion in 6 patients $(0.6$, $95 \%$ CI $0.1-1.1 \%)$, the Greek founder G1738R in 4 patients $(0.4,95 \%$ CI $0.01-08 \%)$, and the exon 20 deletion in 3 patients $(0.3,95 \%$ CI $0.0-0.8 \%)$. Table 1 summarises disease and family history characteristics of the 26 mutation carriers.

Among carriers, the mean age of diagnosis was 42.5 years (range 28-61 years), more than a decade lower than the 53.9 years mean age of onset for the whole cohort. Furthermore, 54\% of the carriers (14 out of 26) belonged to the 'early-onset' group ( $<40$ years) compared to $14 \%$ of the whole cohort. Breast and/or ovarian cancer family history was reported by 17 out of 26 carriers $(65.4 \%)$ compared to $11 \%$ of all consecutive breast cancer patients screened.

It is noteworthy that $10 \%(95 \%$ CI $5.0-15.0 \%)$ of all early-onset patients carry one of the four BRCA1 mutations screened, a fourfold increase from the frequency corresponding to the whole cohort $(2.6 \%)$.

\section{DISCUSSION}

In the present study, we have identified 26 carriers of a BRCA1 germ-line mutation among a hospital-based series of 987 breast cancer patients unselected for family history, specifically screened for the four most common BRCA1 mutations in the Greek population. This is the first report of an effort to provide a reliable frequency of those mutations in Greek breast cancer patients, regarding unselected cases as well as early-onset (below 40 years) cases.

Most population studies include cases selected for strong family history of cancer. These have estimated the prevalence of $B R C A 1$ and BRCA2 mutations in such high-risk families from 20 to $67 \%$ ((Shih et al, 2000; Fackenthal and Olopade, 2007; Palma et al, 2008), and numerous others), where variation is mainly due to study design and population genetic pool, that is founder populations tend to present higher frequencies. There are also numerous studies with populations selected for age of onset. The frequency of $B R C A 1$ and $B R C A 2$ mutations in these studies again varies according to study design (cohort, age that is considered 'early onset', mutation screening techniques) and population. For ages of onset between 35 and 45 years and for Western populations with no strong founder effects, mutation frequency has been estimated from 6 to 13\% for both genes (Peto et al, 1999; Anglian Breast Cancer Study Group, 2000; Malone et al, 2000; Syrjakoski et al, 2000; Loman et al, 2001; de Sanjose et al, 2003; Bonadona et al, 2005; Lubinski et al, 2006). Our findings of a prevalence of 


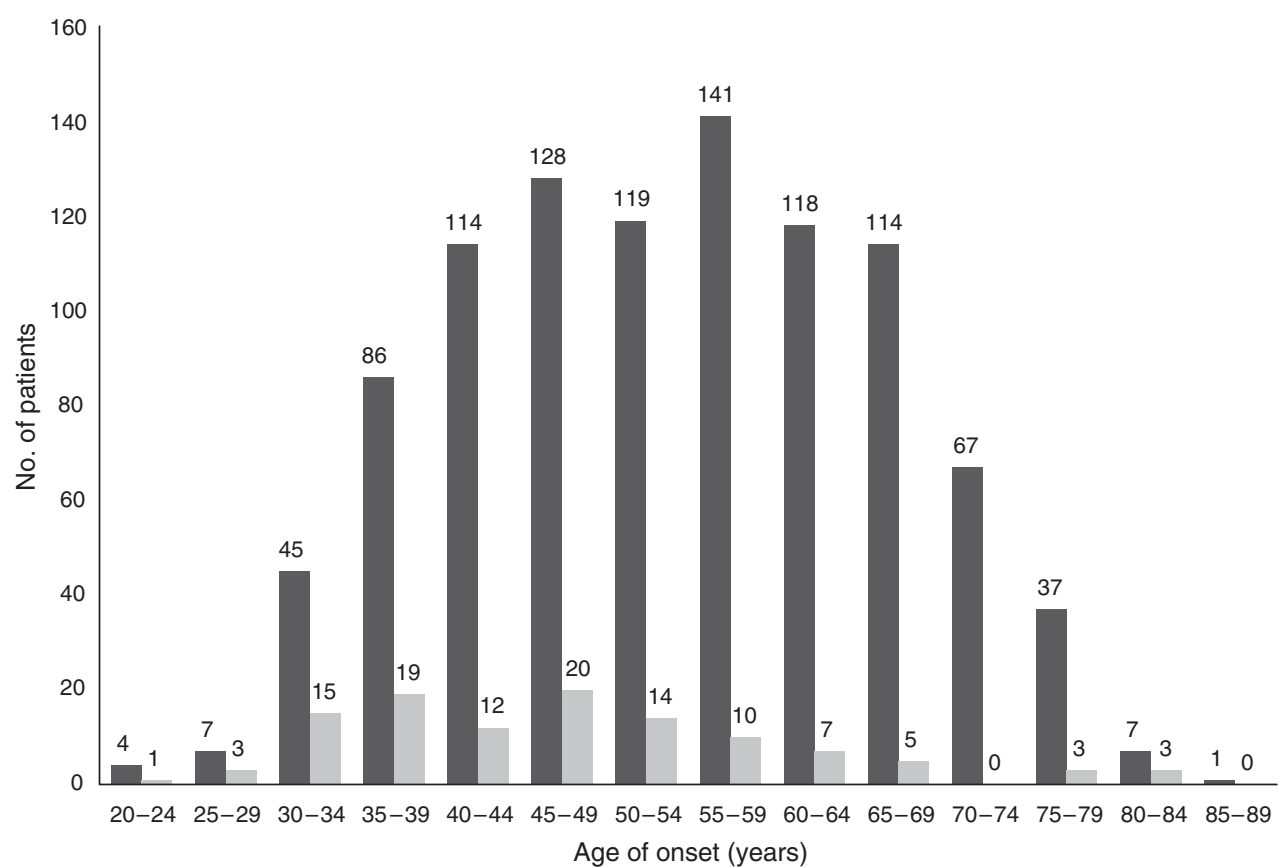

Figure I Age of onset distribution among the 987 consecutive breast cancer patients tested. Black bars depict distribution of the total number of patients, whereas grey bars include only patients with family history.

$10 \%$ for the four common BRCA1 mutations in Greece in earlyonset cases ( $<40$ years) are broadly consistent with the estimates from the previous studies.

Less is known about the prevalence of $B R C A$ mutations in the general population or even in unselected breast cancer cases. Most available data originate from founder populations only screened for their founder mutations (Abeliovich et al, 1997; Thorlacius et al, 1998; Warner et al, 1999). The limited number of studies concerning unselected cases in populations with genetic heterogeneity report a frequency of $1.8-4.7 \%$ for both genes (for a review, see Fackenthal and Olopade (2007)). For BRCA1 only, a mutation frequency of $0.4 \%$ is found in Finnish (Syrjakoski et al, 2000), 2.1\% in Dutch (Papelard et al, 2000), 3\% in Polish (Gorski et al, 2005), <1\% in Swedish (Margolin et al, 2004), $1.5 \%$ in Brazilian (Gomes et al, 2007), and $2.4-3.5 \%$ in US unselected breast cancer patients (Newman et al, 1998; Malone et al, 2006; John et al, 2007). In our present study, we report a total frequency of $2.6 \%$ for the four BRCA1 mutations screened. This result is the minimum estimate and most likely an underestimate of the true frequency of all BRCA1 mutations in Greek breast cancer patients. The Greek BRCA1 and BRCA2 mutation spectrum, as emerged from full screening in high-risk patients, consists of a total of 26 different mutations, 15 in BRCA1 and 11 in BRCA2. Of these, only four $B R C A 1$ mutations are found in $54 \%$ of the families carrying either a $B R C A 1$ or a $B R C A 2$ mutation and in $73 \%$ of the families carrying a BRCA1 mutation (Konstantopoulou et al, 2008). An extrapolation of the present results in an effort to deduce the true frequency of all $B R C A 1$ and BRCA2 mutations in unselected breast cancer patients would suggest that about $4.8 \%$ of all Greek breast cancer patients can be carriers of a $B R C A 1$ or $B R C A 2$ mutation, as the four mutations screened here ( $2.6 \%$ frequency) only represent $54 \%$ of the $B R C A 1 / 2$-positive high-risk families. In the same line, $18 \%$ of all early-onset patients ( $<40$ years) can carry either a $B R C A 1$ or a BRCA2 mutation, given the frequency of $10 \%$ found here for the four common BRCA1 mutations screened. Of the 111 breast cancer patients among our cohort that reported a family history of breast and/or ovarian cancer, 17 have been found to carry one of the four BRCA1 mutations (15.3\%). The lower frequency than the previously reported of $20 \%$ can be explained by our use of less strict criteria to define family history and because screening was limited to the four common mutations.

The two categories in our cohort - that of patients reporting family history and that with early-onset ( $<40$ years) of the disease - are interdependent, that is more than one-third (42 out of 111 , $38 \%$ ) of patients with family history are also early-onset cases (see also Figure 1); vice versa, one-third of early-onset cases (42 out of $140,30 \%$ ) have family history. Of the 42 patients belonging to both groups, 11 carried a mutation $(26 \%)$. Table 2 summarises mutation frequencies for the various categories among our cohort.

Half of the carriers identified in the present study (13 out of 26) have BRCA1 mutation c.5526dup (5382insC). According to previously published results, this mutation accounts for $31 \%$ of the $B R C A 1$ and $B R C A 2$ mutations identified in Greek familial breast/ovarian cancer patients (Ladopoulou et al, 2002; Konstantopoulou et al, 2008). As haplotype analysis has shown, BRCA1 c.5526dup (5382insC) is a 'founder' mutation that originated from the Baltic area and has spread worldwide, but is more prevalent in eastern European and Ashkenazi populations (Neuhausen et al, 1996; Szabo and King, 1997; Hamel et al, 2006; da Costa et al, 2008). The frequency of the mutation revealed here $(1.3 \%)$ is consistent with previous studies performed also in unselected breast cancer patients. A frequency of $1 \%$ is reported in Germany (Backe et al, 1999), of $1.3 \%$ in Brazil (Gomes et al, 2007), of $2.1 \%$ in Poland (Gorski et al, 2005), of 3.7-4\% in Russia (Sokolenko et al, 2006; Bermisheva et al, 2008), and of 2.5-3.8\% for Ashkenazim living in the United States (King et al, 2003) and Canada (Satagopan et al, 2001). Contrary to the case of c.5526dupC, the other three BRCA1 mutations screened here have been found only in Greek patients.

The present findings have important implications for determining the policy for $B R C A 1$ and $B R C A 2$ mutation testing in the Greek population and populations with similar genetic background. It is currently widely accepted that women who fulfil certain criteria based on family history alone or in combination with age of onset should be directed towards $B R C A 1$ and $B R C A 2$ genetic testing. The complexities of the particular test prohibit its recommendation to wider targets, such as all breast cancer patients or even the whole 
Table I Disease history of the 26 breast cancer patients found to carry a BRCA I germ-line mutation

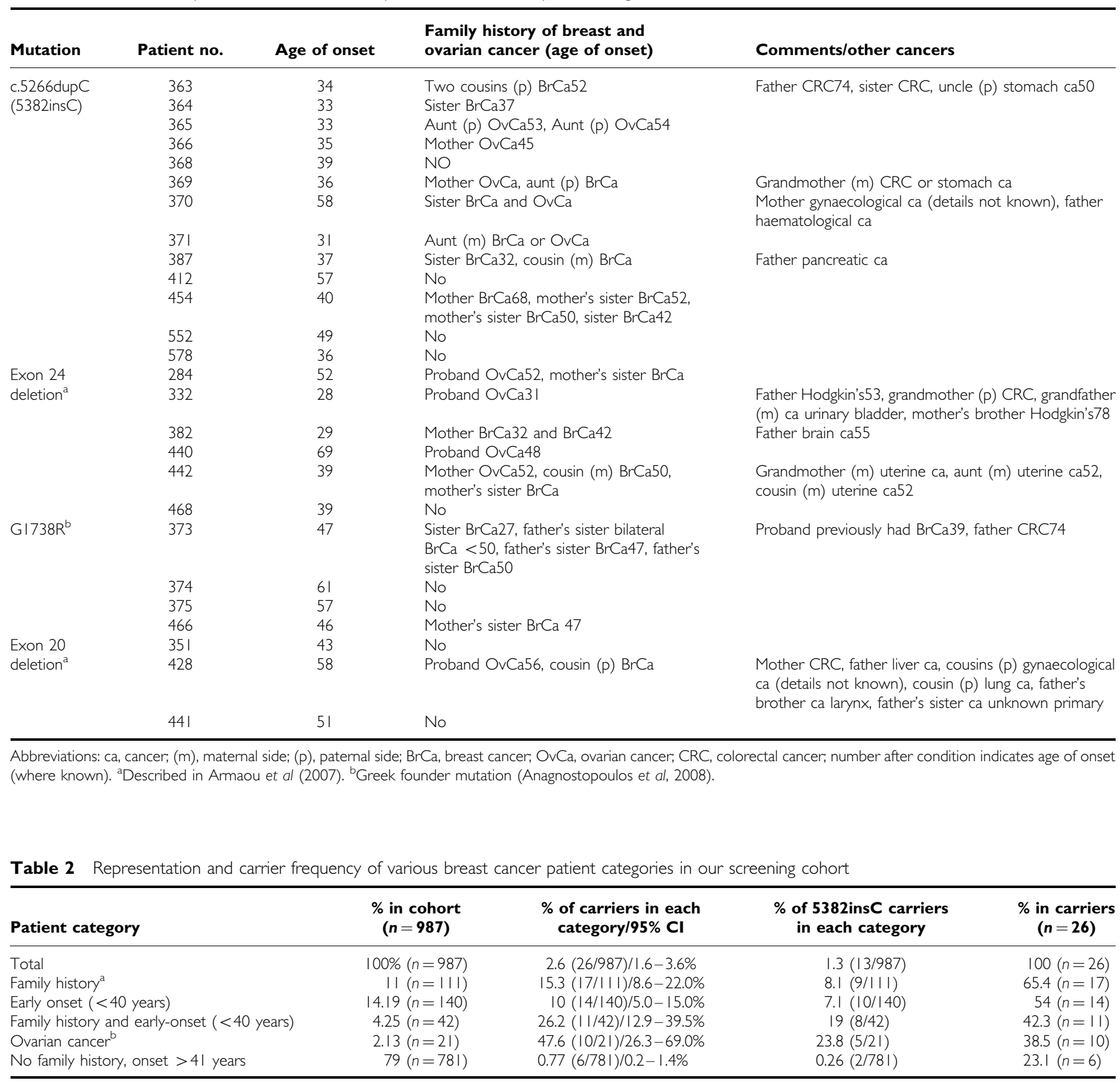

${ }^{\mathrm{a} B y}$ criteria stated in text. ${ }^{\mathrm{b}}$ Personal or family history.

population. However, many mutation carriers who do not fulfil screening criteria have been identified before. We have discovered among our cohort six mutation carriers with no reported family history and with later onset of the disease (Table 2). These cases would have been missed if commonly applied (e.g. two cases of breast cancer before age 50) screening criteria were used. As $B R C A 1$ mutations are highly penetrant and de novo formation is extremely rare, the following factors should be considered as an explanation and taken into account when evaluating patients for referral to genetic testing: misreported family history due to lack of knowledge or unwillingness to share information, limited family structure, greater prevalence of male family members, paternal inheritance, also for Greece the lack of a National Cancer Registry.
To address this matter, we believe that the simplified $B R C A 1$ screening for the four most prevalent Greek mutations designed and employed here should be offered to more women with breast cancer, especially those with an early disease onset and ideally to all breast cancer patients. Furthermore, we propose that all earlyonset patients should be directed towards full BRCA1 and BRCA2 screening as the true frequency of mutations in this group as indicated by our results could be close to $20 \%$.

In conclusion, our results indicate that $2.6 \%$ of the Greek patients developing breast cancer independently of age or family history and $10 \%$ of Greek patients developing breast cancer before age 40 carry one of four common Greek BRCA1 mutations. This finding shows the necessity of a new simplified and focused genetic 
screening approach reaching to a wider population target Our results also imply that recommendation of full screening of the BRCA1 and BRCA2 genes, and even additional predisposing genes, to all breast cancer patients should remain the ultimate goal as new technologies emerge that can lower the cost and effort involved. This point gains additional weight under the view of new personalised therapeutics evolving in the field of oncology.

\section{REFERENCES}

Abeliovich D, Kaduri L, Lerer I, Weinberg N, Amir G, Sagi M, Zlotogora J, Heching N, Peretz T (1997) The founder mutations 185delAG and 5382 insC in BRCA1 and 6174delT in BRCA2 appear in $60 \%$ of ovarian cancer and $30 \%$ of early-onset breast cancer patients among Ashkenazi women. Am J Hum Genet 60: 505 - 514

Anagnostopoulos T, Pertesi M, Konstantopoulou I, Armaou S, Kamakari S, Nasioulas G, Athanasiou A, Dobrovic A, Young MA, Goldgar D, Fountzilas G, Yannoukakos D (2008) G1738R is a BRCA1 founder mutation in Greek breast/ovarian cancer patients: evaluation of its pathogenicity and inferences on its genealogical history. Breast Cancer Res Treat 110: $377-385$

Anglian Breast Cancer Study Group (2000) Prevalence and penetrance of BRCA1 and BRCA2 mutations in a population-based series of breast cancer cases. Br J Cancer 83: $1301-1308$

Armaou S, Konstantopoulou I, Anagnostopoulos T, Razis E, Boukovinas I, Xenidis N, Fountzilas G, Yannoukakos D (2007) Novel genomic rearrangements in the BRCA1 gene detected in Greek breast/ovarian cancer patients. Eur J Cancer 43: $443-453$

Backe J, Hofferbert S, Skawran B, Dork T, Stuhrmann M, Karstens JH, Untch M, Meindl A, Burgemeister R, Chang-Claude J, Weber BH (1999) Frequency of BRCA1 mutation 5382insC in German breast cancer patients. Gynecol Oncol 72: 402-406

Bermisheva MA, Zinnamullina GF, Gantsev S, Kochanova VA, Popov OS, Dork T, Khusnutdinova EK (2008) [Frequency of 5382insC mutation of the BRCA1 gene]. Vopr Onkol 54: $31-33$

Bonadona V, Sinilnikova OM, Chopin S, Antoniou AC, Mignotte H, Mathevet P, Bremond A, Martin A, Bobin JY, Romestaing P, Raudrant D, Rudigoz RC, Leone M, Chauvin F, Easton DF, Lenoir GM, Lasset C (2005) Contribution of BRCA1 and BRCA2 germ-line mutations to the incidence of breast cancer in young women: results from a prospective population-based study in France. Genes Chromosomes Cancer 43: $404-413$

Chan PC, Wong BY, Ozcelik H, Cole DE (1999) Simple and rapid detection of BRCA1 and BRCA2 mutations by multiplex mutagenically separated PCR. Clin Chem 45: 1285-1287

da Costa EC, Vargas FR, Moreira AS, Lourenco JJ, Caleffi M, Ashton-Prolla P, Martins Moreira MA (2008) Founder effect of the BRCA1 5382insC mutation in Brazilian patients with hereditary breast ovary cancer syndrome. Cancer Genet Cytogenet 184: 62-66

De Greve J, Sermijn E, De Brakeleer S, Ren Z, Teugels E (2008) Hereditary breast cancer: from bench to bedside. Curr Opin Oncol 20: 605-613

de Sanjose S, Leone M, Berez V, Izquierdo A, Font R, Brunet JM, Louat T, Vilardell L, Borras J, Viladiu P, Bosch FX, Lenoir GM, Sinilnikova OM (2003) Prevalence of BRCA1 and BRCA2 germline mutations in young breast cancer patients: a population-based study. Int J Cancer 106: $588-593$

Fackenthal JD, Olopade OI (2007) Breast cancer risk associated with BRCA1 and BRCA2 in diverse populations. Nat Rev 7: 937-948

Ferla R, Calo V, Cascio S, Rinaldi G, Badalamenti G, Carreca I, Surmacz E, Colucci G, Bazan V, Russo A (2007) Founder mutations in BRCA1 and BRCA2 genes. Ann Oncol 18(Suppl 6): vi93 - vi98

Gomes MC, Costa MM, Borojevic R, Monteiro AN, Vieira R, Koifman S, Koifman RJ, Li S, Royer R, Zhang S, Narod SA (2007) Prevalence of BRCA1 and BRCA2 mutations in breast cancer patients from Brazil. Breast Cancer Res Treat 103: $349-353$

Gorski B, Cybulski C, Huzarski T, Byrski T, Gronwald J, Jakubowska A, Stawicka M, Gozdecka-Grodecka S, Szwiec M, Urbanski K, Mitus J, Marczyk E, Dziuba J, Wandzel P, Surdyka D, Haus O, Janiszewska H, Debniak T, Toloczko-Grabarek A, Medrek K, Masojc B, Mierzejewski M, Kowalska E, Narod SA, Lubinski J (2005) Breast cancer predisposing alleles in Poland. Breast Cancer Res Treat 92: 19-24

\section{ACKNOWLEDGEMENTS}

We thank the patients for their willingness to collaborate in this study. This work was partly supported by a Hellenic Cooperative Oncology Group research grant (HR R_BG/04), the Greek Ministry of Health \& Welfare (MOHAW) and the Greek General Secretary for Research and Technology (GSRT) Program, Research in Excellence II, funded by $75 \%$ from the European Union.

Hamel N FL, Narod SA, Tihomirova L, Zajac V, Ciernikova S, Armaou S, Yannoukakos D, Greenwood C, Foulkes WD (2006) Investigating the origins of the BRCA1 mutation c.5385dupC. In: Abstracts of the 56th Annual Meeting of the American Society of Human Genetics. New Orleans, LA, USA. 203

John EM, Miron A, Gong G, Phipps AI, Felberg A, Li FP, West DW, Whittemore AS (2007) Prevalence of pathogenic BRCA1 mutation carriers in 5 US racial/ethnic groups. JAMA 298: 2869-2876

King MC, Marks JH, Mandell JB (2003) Breast and ovarian cancer risks due to inherited mutations in BRCA1 and BRCA2. Science 302: 643-646

Konstantopoulou I, Rampias T, Ladopoulou A, Koutsodontis G, Armaou S, Anagnostopoulos T, Nikolopoulos G, Kamakari S, Nounesis G, Stylianakis A, Karanikiotis C, Razis E, Gogas H, Keramopoulos A, Gaki V, Markopoulos C, Skarlos D, Pandis N, Bei T, Arzimanoglou I, Fountzilas G, Yannoukakos D (2008) Greek BRCA1 and BRCA2 mutation spectrum: two BRCA1 mutations account for half the carriers found among high-risk breast/ovarian cancer patients. Breast Cancer Res Treat 107: $431-441$

Ladopoulou A, Kroupis C, Konstantopoulou I, Ioannidou-Mouzaka L, Schofield AC, Pantazidis A, Armaou S, Tsiagas I, Lianidou E, Efstathiou E, Tsionou C, Panopoulos C, Mihalatos M, Nasioulas G, Skarlos D, Haites NE, Fountzilas G, Pandis N, Yannoukakos D (2002) Germ line BRCA1 \& BRCA2 mutations in Greek breast/ovarian cancer families: 5382insC is the most frequent mutation observed. Cancer Lett 185: 61-70

Loman N, Johannsson O, Kristoffersson U, Olsson H, Borg A (2001) Family history of breast and ovarian cancers and BRCA1 and BRCA2 mutations in a population-based series of early-onset breast cancer. J Natl Cancer Inst 93: $1215-1223$

Lubinski J, Gorski B, Huzarski T, Byrski T, Gronwald J, Serrano-Fernandez P, Domagala W, Chosia M, Ucinski M, Grzybowska E, Lange D, Maka B, Mackiewicz A, Karczewska A, Breborowicz J, Lamperska K, Stawicka M, Gozdecka-Grodecka S, Bebenek M, Sorokin D, Wojnar A, Haus O, Sir J, Mierzwa T, Niepsuj S, Gugala K, Gozdz S, Sygut J, Kozak-Klonowska B, Musiatowicz B, Posmyk M, Kordek R, Morawiec M, Zambrano O, Wasko B, Fudali L, Skret J, Surdyka D, Urbanski K, Mitus J, Rys J, Szwiec M, Rozmiarek A, Dziuba I, Wandzel P, Wisniowski R, Szczylik C, Kozak A, Kozlowski W, Narod SA (2006) BRCA1-positive breast cancers in young women from Poland. Breast Cancer Res Treat 99: 71 -76

Malone KE, Daling JR, Doody DR, Hsu L, Bernstein L, Coates RJ, Marchbanks PA, Simon MS, McDonald JA, Norman SA, Strom BL, Burkman RT, Ursin G, Deapen D, Weiss LK, Folger S, Madeoy JJ, Friedrichsen DM, Suter NM, Humphrey MC, Spirtas R, Ostrander EA (2006) Prevalence and predictors of BRCA1 and BRCA2 mutations in a population-based study of breast cancer in white and black American women ages 35 to 64 years. Cancer Res 66: 8297-8308

Malone KE, Daling JR, Neal C, Suter NM, O’Brien C, Cushing-Haugen K, Jonasdottir TJ, Thompson JD, Ostrander EA (2000) Frequency of BRCA1/ BRCA2 mutations in a population-based sample of young breast carcinoma cases. Cancer 88: $1393-1402$

Margolin S, Werelius B, Fornander T, Lindblom A (2004) BRCA1 mutations in a population-based study of breast cancer in Stockholm County. Genet Test 8: $127-132$

Neuhausen SL (2000) Founder populations and their uses for breast cancer genetics. Breast Cancer Res 2: 77-81

Neuhausen SL, Mazoyer S, Friedman L, Stratton M, Offit K, Caligo A, Tomlinson G, Cannon-Albright L, Bishop T, Kelsell D, Solomon E, Weber B, Couch F, Struewing J, Tonin P, Durocher F, Narod S, Skolnick MH, Lenoir G, Serova O, Ponder B, Stoppa-Lyonnet D, Easton D, King MC, Goldgar DE (1996) Haplotype and phenotype analysis of six recurrent BRCA1 mutations in 61 families: results of an international study. $A m J$ Hum Genet 58: $271-280$ 
Newman B, Mu H, Butler LM, Millikan RC, Moorman PG, King MC (1998) Frequency of breast cancer attributable to BRCA1 in a population-based series of American women. JAMA 279: 915-921

Palma MD, Domchek SM, Stopfer J, Erlichman J, Siegfried JD, TiggesCardwell J, Mason BA, Rebbeck TR, Nathanson KL (2008) The relative contribution of point mutations and genomic rearrangements in BRCA1 and BRCA2 in high-risk breast cancer families. Cancer Res 68: 7006-7014

Papelard H, de Bock GH, van Eijk R, Vliet Vlieland TP, Cornelisse CJ, Devilee P, Tollenaar RA (2000) Prevalence of BRCA1 in a hospital-based population of Dutch breast cancer patients. Br J Cancer 83: 719-724

Parkin DM, Bray F, Ferlay J, Pisani P (2005) Global cancer statistics, 2002. CA Cancer J Clin 55: 74-108

Peto J, Collins N, Barfoot R, Seal S, Warren W, Rahman N, Easton DF, Evans C, Deacon J, Stratton MR (1999) Prevalence of BRCA1 and BRCA2 gene mutations in patients with early-onset breast cancer. J Natl Cancer Inst 91: $943-949$

Robson M, Offit K (2007) Clinical practice. Management of an inherited predisposition to breast cancer. New Engl J Med 357: 154-162

Satagopan JM, Offit K, Foulkes W, Robson ME, Wacholder S, Eng CM, Karp SE, Begg CB (2001) The lifetime risks of breast cancer in Ashkenazi Jewish carriers of BRCA1 and BRCA2 mutations. Cancer Epidemiol Biomarkers Prev 10: $467-473$

Shih HA, Nathanson KL, Seal S, Collins N, Stratton MR, Rebbeck TR, Weber BL (2000) BRCA1 and BRCA2 mutations in breast cancer families with multiple primary cancers. Clin Cancer Res 6: 4259-4264
Sokolenko AP, Mitiushkina NV, Buslov KG, Bit-Sava EM, Iyevleva AG, Chekmariova EV, Kuligina E, Ulibina YM, Rozanov ME, Suspitsin EN, Matsko DE, Chagunava OL, Trofimov DY, Devilee P, Cornelisse C, Togo AV, Semiglazov VF, Imyanitov EN (2006) High frequency of BRCA1 5382insC mutation in Russian breast cancer patients. Eur J Cancer 42: $1380-1384$

Syrjakoski K, Vahteristo P, Eerola H, Tamminen A, Kivinummi K, Sarantaus L, Holli K, Blomqvist C, Kallioniemi OP, Kainu T, Nevanlinna $\mathrm{H}$ (2000) Population-based study of BRCA1 and BRCA2 mutations in 1035 unselected Finnish breast cancer patients. J Natl Cancer Inst 92: $1529-1531$

Szabo CI, King MC (1997) Population genetics of BRCA1 and BRCA2. Am J Hum Genet 60: $1013-1020$

Thorlacius S, Struewing JP, Hartge P, Olafsdottir GH, Sigvaldason H, Tryggvadottir L, Wacholder S, Tulinius H, Eyfjord JE (1998) Populationbased study of risk of breast cancer in carriers of BRCA2 mutation. Lancet 352: $1337-1339$

Walsh T, King MC (2007) Ten genes for inherited breast cancer. Cancer Cell 11: $103-105$

Warner E, Foulkes W, Goodwin P, Meschino W, Blondal J, Paterson C, Ozcelik H, Goss P, Allingham-Hawkins D, Hamel N, Di Prospero L, Contiga V, Serruya C, Klein M, Moslehi R, Honeyford J, Liede A, Glendon G, Brunet JS, Narod S (1999) Prevalence and penetrance of BRCA1 and BRCA2 gene mutations in unselected Ashkenazi Jewish women with breast cancer. J Natl Cancer Inst 91: 1241 - 1247 